\title{
Building Partnerships and Fostering Activities to Promote English Outside the Classroom
}

\author{
Ángel Raluy Alonso \\ University of Vic \\ angel.raluy@uvic.cat
}

\begin{abstract}
Becoming proficient in at least one foreign language is a target for educational authorities throughout Europe. The question is how we can improve our students' command of English without increasing the workload on teachers and without much funding. In El Prat de Llobregat, a city located in the vicinity of Barcelona, we have addressed that issue by creating a group of teachers, educational advisors and city council administrators, who have been acting in a coordinated way to enhance English language exposure beyond the classroom. Our interest in promoting English stems from our location: our municipality is situated next to an international airport where finding a job is bound to be dependent on English fluency. We aim to show that, through a network of members at school and administrative levels, an array of meaningful and empowering initiatives can be implemented in a city where resources are scarce and cultural backgrounds diverse.
\end{abstract}

\section{Introduction}

It is common knowledge among educators and school administrators that becoming proficient in at least one foreign language (other than Spanish and Catalan, in our case) is crucial. Although the study of trilingualism is still in its infancy, researchers have found that knowing three languages seems to open doors to a multitude of opportunities. Ricciardelli (1992) states that multilinguals are more creative and have 
better problem-solving skills than monolinguals or bilinguals. Their ability to approach problems from a variety of angles is seen to be a result of tools acquired through learning an L2. Tokuhama-Espinosa (2003:1-8) concurs with this idea and proves untrue the myth that multilingualism leads to language problems and notes that abilities in L2 will have a positive effect on any subsequent languages learned. Our municipality believes that every student deserves to be able to become multilingual and even more so in El Prat de Llobregat, whose main employer is Barcelona International Airport. Indeed many career opportunities are and will be awaiting those individuals who communicate well in Spanish, Catalan and English, but the current three or four hours a week of foreign language school instruction seem to mean students fall short of attaining the proficiency goal required in fluent communication. Thus, we have turned to out-of-class learning (OCLL) as a way to promote language competence in our student body. Research in this area has been vague but, as Bialystok (1981:24-35) early on concluded, out-of-class exposure to the target language in communicative situations is critical to the development of all language skills. She also asserted that learners get the most benefit from formal language instruction when it is coupled with opportunities for natural exposure to the language. Obviously, the context in which OCLL occurs has been a recurring theme in many studies. Going abroad has frequently been mentioned as the main source of language learning, but since that possibility is out of reach for many of our learners we need to rely on a non-native speaker environment to fulfil that mission.

Research has proven therefore the need for extra exposure but the question still stands as to how we could provide real students with opportunities to engage in meaningful communication. Our answer states that parents, teachers, schools, municipalities cannot meet those needs unless they work in a coordinated way.

\section{Group Structure}

The idea of starting a working group sprang from a small number of teachers, and municipal advisors in the fall of 2004. We were all anxious to spread English in the community, and convinced that local initiatives can have a very positive impact on school effectiveness as proved by Riley, Docking and Rowles, (1998). Likewise, we endeavoured to develop a "Community Learning Network", that is, a community-based group of individuals belonging to different fields (governmental, institutional or even corporate-driven) who promote and support English learning in the community. The following diagram (Figure 1) may clarify our pattern of communication and relationships within our group whose name is El Prat s'obre al món: l'anglès n'és la clau (El Prat opens up to the world. English is the key) 


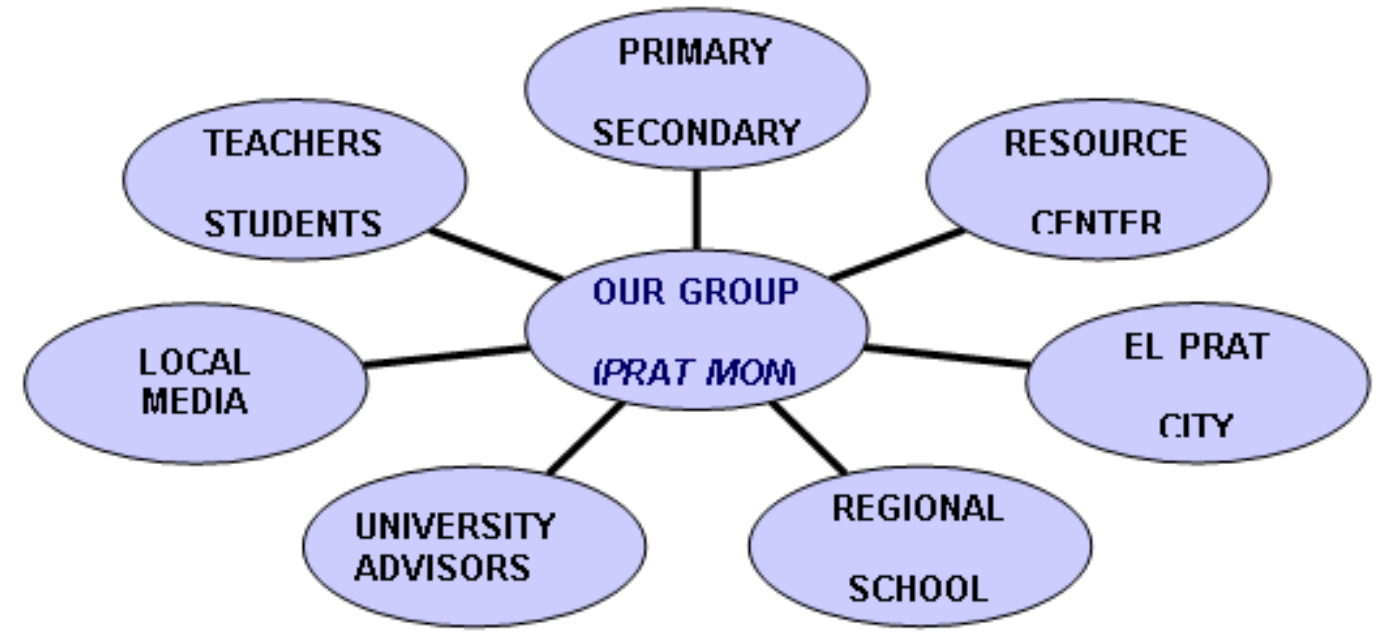

Our philosophy highlights team spirit over top down approaches, since all the partners participate voluntarily. Tasks are distributed according to areas of influence in order to save time and energy. Teachers, local educational advisors, and school board members have an equal voice and their contributions reflect the different and sometimes conflicting views between the school and the administrative levels. Nonetheless, there is a coordination team composed by a university teacher, the local resource centre director and a school advisor who set up meetings, schedule activities and most importantly serve as a reference point for the other partners. This coordinating effort is also made on a volunteer basis. Meetings have been kept to a minimum and we have instead relied on virtual tools for communication. The circulation of information has probably been the biggest challenge we have faced over the years and a permanent source of concern. Initially, we created a blog http://blocs.xtec.cat/anglesprat/benvinguda/ as a communication tool. The advantage of blogs is that they are free, need very little training to manage and have no cost whatsoever. Even if our blog has proved effective for three years we are acutely aware of its limitations of interaction. Therefore, we have begun to develop an online moodle platform with a three fold purpose: guarantee a sustainable sharing environment, enhance peer contributions and, above all, make access easier for partners and teachers since the knowledge of Moodle platforms is widespread in the educational community.

\section{Actions}

We have fostered a number of actions to help our students increase their linguistic competence and they can be easily arranged into 3 main categories: activities for primary and secondary students, activities for teachers, and activities for citizens of El Prat. 


\subsection{Activities for primary and secondary school students}

As for the activities designed for primary and secondary school students, we promote a radio program called Time for English, we bring theatre performances to our city, we organize a school exchange experience with Fingal County in Ireland, and we coordinate a school summer camp.

The idea of broadcasting a radio programme in English came into existence after a meeting with the local radio station (El Prat Ràdio) in 2006. The staff at the radio station were eager to open up its doors, and keen to facilitate the students' recordings by offering their technical support and communication expertise. The initial four public secondary schools which volunteered to participate in the experience have become six with the addition of two more private ones. A virtual network to harmonize proposals has been developed over the years, but each school has kept certain autonomy when it comes to changing content. Topics vary from music, movie reviews, day trips, video games, and they are a clear indicator of teenage worries and concerns. Within each school, there is a fixed core of collaborators (around five or six) who supervise the production of the programme even if their work is eventually checked by a teacher or a language assistant. A recording calendar is determined at the beginning of each academic year and includes the year-round schedule for participating schools. Broadcasting in a foreign language has proved challenging to our teenagers, even to competent language students, so extensive rehearsals have been imperative to build self-confidence especially during the students' first recording sessions. Participants have consistently placed a high value on the activity and, in fact, it has surpassed expectations: as an unexpected outcome some pupils have started collaborating with the local radio on a regular basis at the weekends.

We also bring an English speaking theatre company called Blue Mango to our city on the assumption that drama provides excellent grounds for development of their imagination and students' empathy. Indeed McCaslin, (1996:73) affirms that theatrical activities enhance independent thinking and add motivation to the learning process while contextualizing acquisition of new vocabulary and structures. In this sense, The Blue Mango company helps teachers put the shows in context by previously providing teaching materials (audio, video, lesson plans) to prepare students for what will be performed on stage. Plays tend to cover primary and secondary school topics such as bullying, recycling, multiculturalism, or peer pressure, and are staged in a municipal venue to reduce costs. After the plays, pupils organize acting out sessions which recreate what they saw and their plays are also performed at school festivals. As Table 2 shows, the number of students who attend the performances has steadily increased over the past three years: 


\begin{tabular}{|l|l|l|l|}
\hline & $\mathbf{2 0 0 8}$ & $\mathbf{2 0 0 9}$ & $\mathbf{2 0 1 0}$ \\
\hline $1^{\text {st }}$ and $2^{\text {nd }}$ grade students & 50 & 481 & 671 \\
\hline $3^{\text {rd }}$ and $4^{\text {th }}$ grade students & 448 & 428 & 701 \\
\hline $5^{\text {th }}$ and $6^{\text {th }}$ grade students & 594 & 666 & 598 \\
\hline $1^{\text {st }}$ cycle secondary school students & 154 & 396 & 219 \\
\hline $2^{\text {nd }}$ cycle secondary school students & 288 & 479 & 562 \\
\hline High school students & 166 & 171 & 256 \\
\hline Adult students & 25 & 18 & 0 \\
\hline TOTAL & 1,725 & 2,639 & 3,007 \\
\hline
\end{tabular}

The School Exchange started in 2007 as a result of a twin city agreement between our municipality and Fingal City Council in Ireland. In order to prepare students for international field experiences, we followed Mahna and Stachowski's approach (1995:52-59). They strongly recommend onsite academic assignments, school integration, host family accommodation, and follow-up evaluation to maximize the students' exposure to the target language. Thus, we contacted St Joseph's secondary school in Fingal County and four secondary schools from El Prat. The first exchange laid the groundwork for future visits for students' age (over 16); length (seven days), candidates (24/26), hosting requirements, overall academic performance (weaker students are encouraged to pass all their subjects to participate) and foreign language interest, which is a sine qua non condition.

However, throughout the years, the experience has moved beyond a mere cultural activity, and has developed more educational overtones. In this sense, the cornerstone is a "song project" in which students write, then record their own songs and finally take them to the stage for a final performance. The activity itself starts on the first part of the exchange with preparation for song writing, DVD making and performing. At the end of this first exchange visit, the pupils put on a preliminary show with their newly written material and make a presentation of the production process. Over the next few months students work cooperatively on their musical compositions through a website http://songschool.ie/new/songschool/ where they keep in touch and share ideas to improve their final performances for the second visit. This joint performance is offered to the community and is completed with an exhibition of photographs. The song project has proved to be helpful to let students express themselves through music, but it has mainly contributed to preventing cliques, which are very likely to form in many exchange experiences.

By and large, English summer schools have traditionally been available only to elitist private schools, wealthy parents who could send their offspring abroad or, in Catalonia, to some scholarship holders who were allowed on the summer camps organized by the Catalan Department of Education. Our beliefs have always been to make summer school activities accessible to all our city pupils regardless of their economic situation. The benefits of English summer camps are obvious and have been studied among others by Weighting (2005: 85-108) who emphasizes: 
the synergistic interaction of three elements: the camp context, the interactive nature of the teaching activities and the opportunity to use English for authentic purposes...language camps provide students with rich and authentic language experiences.

Bearing this evidence in mind, El Prat city council started organizing the camp with the help of a non-profit voluntary association Fundació Catalana de l'Esplai in 2007. At first the experience was disappointing: few students enrolled and parents expressed a preference for housing the summer school in a school setting not in a private holder's venue. Hence it was decided that a private company, Kith Institute, should be hired to organize the summer activities for primary students in a local public school. The camp started in 2009 and it was an instant success, as reflected in enrolment figures in Fig. 3:

\begin{tabular}{|l|l|l|}
\hline Summer School Enrolment & 2009 & 2010 \\
\hline Pre-school & 82 & 94 \\
\hline $1^{\text {st }}$ and $2^{\text {nd }}$ graders & 55 & 65 \\
\hline $3^{\text {rd }}$ and $4^{\text {th }}$ graders & 38 & 45 \\
\hline $5^{\text {th }}$ and $6^{\text {th }}$ graders & 15 & 19 \\
\hline
\end{tabular}

For primary and pre-school pupils the activities are held at a public primary school according to a fixed schedule. It starts with story-telling, continues with paper and pencil activities and moves to team games, and outdoor activities. Older students carry out projects that are presented to other pupils in an assembly form. Each week an educational day trip is also organized to enhance English learning outside the classroom Parents can choose from 3 possible pickup times, either at 1:00 p.m. 3:00 p.m. or 5:00 p.m. although after 3:00 p.m. recreational activities such as watching films or play time are implemented. On the whole, it is conceived as a summer activity so the language input is vehicled through oral and listening tasks, not so much through worksheets and lesson plans.

For secondary students a song school's creative English workshop was set up in the summer of 2010. The idea was to offer the possibility to motivate teenagers to speak English to native speakers while engaging in music writing and video making within a two-week workshop. Based on the exchange music project designed by the Irish Song School, participants created and performed their own show. Apart from the Irish musicians, some exchange participants volunteered to assist with music and other arrangements. Their collaboration was seen as extremely valuable because they provided positive reinforcement as local role models, and strongly contributed to reducing participants' language anxiety. Both parents and students who took part in the activity expressed very positive views about their interpersonal and linguistic gains.

\subsection{Activities for teachers and schools}

The central activities designed for teachers are: teacher training courses, conference organization and hosting of European visiting schools. 
Our group wholeheartedly believes that teacher training is essential to enhance the quality of our country's foreign language instruction but we have opted for concentrating on language proficiency following Berry (1990: 97-105). He reports that teacher-training programs should virtually exclude the methodological aspect and concentrate on the improvement of the language level per se. He also states that, in regions where English is not a medium of instruction, the main interest of English teachers is to improve their own command of the language so that they can use it more confidently in the classroom. Of course, our group is not in a position to set up training courses so we focus our efforts on alternative workshops. In 2009 a drama training course called Act English was jointly organized with the theatre company Blue Mango. As Kao and O'Neill (1998: 167) affirm: “drama provides contexts for multiple language encounters and encourages authentic dialogue" and in the belief that interacting with an English professional actor could help improve teachers' language proficiency we supported the seminar. The training was intended for 15 teachers in primary and secondary schools and it consisted of six sessions dealing with different aspects of the use of drama in the ELT classroom. Mainly trainees took part in drama games, which were aimed at improving their language competence and interpersonal communication skills, and also discussed the varying suitability of these games for different classes.

Together with training we are convinced that professional growth is a key to success and this is why we have set up a biennial local workshop to share good practices in English language teaching. In 2008 the first training day called "Sharing experiences to strengthen our teaching practice" was set in motion. The workshop had 12 speakers and 25 participants both from secondary and primary school levels. The main purpose was to share experiences, which had been successfully implemented and which could be replicated. It was not meant to be a formal conference, but more of "an in-service day which would encourage sharing in a friendly local environment where, by developing such communal awareness, language teachers will inevitably become more and more engaged in their professional organizations." (Di Donato 1983 21-26)

Finally, our group has encouraged the visit of other European school districts for short, structured professional experiences as an opportunity to see first hand how others respond to broadly similar problems in education. Teachers and administrators from West Dunbartonshire Council in Scotland and from Reading School district in England came over to observe our language immersion experiences and to analyse our art programmes both in Catalan and English. These visits have provided a professional development opportunity for our teachers and school administrators to work together on issues of mutual interest. Anyhow, in order to maximize possible benefits, there is an urgent need for an adequate framework for observation and study, because time should not be devoted to go over basic information or to uproot cultural prejudices. As Trethewey summarizes (1993: 88-93): "it is necessary to have devised a framework of study and to have asked visitors to do a considerable amount of background reading before leaving home." 


\subsection{Activities for El Prat citizens}

The last leg of this three-legged stool consists of two activities: an English book club for adult citizens and a regular screening of films in English with Spanish subtitles at the local cinema.

Extensive reading is said to have important benefits for older adults. Among many others Rane-Szostak (1997) suggests that ER (Extensive Readig) is associated with decreased loneliness and enhanced feelings of self-worth among learning adults. Her research also implies that book clubs can offer a way of motivating learners to develop their listening and speaking skills through reading. Thus, we targeted adult learners at a minimum B2 level of the Common European Framework to start a book club. Initially, the ten principles for extensive reading (Bamford and Day 2004: 2-3) served as a starting point for this book club project but, since our participants were middle-aged people, we decided to have a less structured atmosphere. We understood that a lower pressure would facilitate a freer language practice among our adult learners so we bypassed some of Bamford's strict guidelines on teacher orientation. We were unable as well to let learners choose what they wanted to read because of limitations in book stocks. Instead both a librarian and the book club facilitator elaborated a preliminary reading list based on book availability at the library network, expected group interests, and variety of genres. In groups no larger than 15, sessions are held on a monthly basis at the local library and participants check the next reading material after each meeting. According to participants, the book club experiment has provided a window of opportunity for speaking although more research should be conducted in order to give enough evidence of its impact on overall motivation for life-long learning.

Jane King (2002: 509-523) highlights the importance of feature films in language learning because: "they bring language to life by providing valuable insight into colloquial English spoken by different native speaker voices...in real life situations." In Spain, the benefits of watching films in English are even more so, because dubbing is a generalized practice and therefore exposure to the foreign language is not readily accessible. Thus, together with the local department of culture and the friends of Unesco association a bimonthly free film screening in English is organized at the local cinema. The movies, ranging from Blade Runner or Clockwork Orange to The Kite Runner or The Visitor, are shown in original version with Spanish subtitles. Even if watching films with subtitles has been regarded as a support practice that tended to slow down the development of listening skills, we concur with Vanderplank's studies (1988: 272-273) that:

far from being a distraction... subtitles might have a potential value in ...providing learners with the key to massive quantities of authentic and comprehensible language input...subtitles help enhance a feeling of security on learning which may lead students to watching films unsupported by text 


\section{Conclusions and future challenges}

It is widely accepted that knowing English paves the way for students'success in the twenty-first century. Nevertheless, becoming truly proficient in a foreign language seems to be an unattainable goal if language competence is not enhanced outside the classroom. If we want our students and citizens to gain both the power and the pleasure of communicating effectively in English we need to maximize their language exposure through different activities. In this paper, we have presented how a group of committed individuals representing schools, local authorities, media, and the school administration can help promote English in a mid-size city by creating networks. We have used foreign language research as general guidelines of how students may enhance their language competence. As for our group structure, we rely on a top down approach which neither hinders our effectiveness nor establishes a paralysing hierarchy, but allows a free flow of ideas. By establishing partnerships and working online, our volunteer work has managed to implement activities which target students, schools and citizens of El Prat. School exchanges, drama activities, summer schools, teacher meetings, book clubs, and radio programmes are examples of initiatives aimed at different levels.

When it comes to future challenges, further research, group continuity, coordination among team members and visibility should be prioritised. We are aware that many of our initiatives need more studies to validate its impact on students and its benefits for our city language learners. Our fundamental goal would be to determine which activities best or more frequently lead to improvements in language proficiency. In this sense, we are trying to start a line of collaborative classroom research with several schools so as to become better informed about the effectiveness of the activities.

In roughly six years of its existence, turnover has posed a serious problem to the group cohesion. Due to its volunteer membership, frequent changes in representatives have been the unfortunate norm and they have had a negative impact on group cohesion and action follow-up. Team members ought to last for at least two years in order to give continuity to their work, and school administrations should be flexible enough to allow teachers' involvement in the project even if that means meeting during school hours. Coordination is also crucial to ensure a proper circulation of the information, which will inevitably result in a better use of time and energy. Efforts should be made to maximize online communication through platforms such a moodle. This e-learning software platform will help make interaction more fluent and will boost collaborative construction of content between group members, teachers and students.

Finally, we should focus on group visibility. Improving our presence in the teaching community is pivotal because we need to engage more classroom teachers and we would like to have more support from the regional department of education. In this sense, we have begun presenting our model and results in international conferences but we often lack administrative support to attend meetings or to host international visitors. In the past, the regional board of education contributed to our expenses but nowadays we need to rely on the local council sponsorship to cover our basic group needs which has turned to be a never-ending struggle. All in all, we have attempted to present a 
comprehensive guide to ways of promoting the English language outside the school environment. By establishing collaboration with teachers, school administrations and the larger community we have developed a network of agents who have been able to activate many language actions in our city. The underlying message of this paper is that all institutions involved in foreign language teaching should join hands in helping our citizens become multilinguals.

\section{Notes}

1. A funded Comenius Regio project called "Building European Citizenship through Children Literature" has sprang from one of these institutional visits.

2 . The ten principles are: 1 . The reading material is easy. 2 . A variety of reading material on a wide range of topics is available. 3. Learners choose what they want to read. 4. Learners read as much as possible. 5. Reading speed is usually faster rather than slower. 6 . The purpose of reading is usually related to pleasure, information, and general understanding 7 . Reading is individual and silent. 8. Reading is its own reward. 9. The teacher orients and guides the students. 10. The teacher is a role model of a reader.

3. Acommunication entitled: "Creating networks and building partnerships to promote the foreign language outside the classroom: a new city perspective in El Prat de Llobregat" was presented at the I International Conference on Bilingual Teaching in Educational Institutions.

\section{References}

Bamford, J. and R. Day (2004): Extensive Reading Activities For Teaching Language. Cambridge: Cambridge University Press.

Berry, R. (1990): "The role of language improvement in in-service teacher training programmes: Killing two birds with one stone." System 18/1: 97-105.

Bialystok, E. (1981): "The role of conscious strategies in second language proficiency" Modern Language Journal 65/2: 24-35.

Di Donato R. (1983): "Taking the Conference to the Teachers: Workshops to Improve Language Teaching" Foreign Language Annals 16/I: 21-26 February

Kao, S. and C. O'Neill (1998): Words into Worlds: Learning a Second Language through Process Learning. Ablex Publishing Corporation, CT.

King, J. (2002): "Using DVD feature films in the EFL classroom", in Computer Assisted Language Learning 15/5: 509-523.

Mahan, J.M. and L.L. Stachowski (1995): Emerging Trends in Teacher Preparation: The Future Of Field Experiences. Thousand Oaks, CA: Corwin Press.

McCaslin, N. (1996): Creative Drama in the Classroom and Beyond. New York: Longman.

Rane-Szostak, D. (1997): Successful Strategies for Extensive Reading, ed. by G.M. Jacobs, C. Davis, and W.A. Renandya. Singapore: SEAMEO Regional Language Centre.

Ricciardelli, L.A. (1992): "Bilingualism and cognitive development in relation to threshold theory." Journal of Psycholinguistic Research 21, 301-316. 
Riley, X., J. Docking and D. Rowles (1998): "Local Education Authorities in England: Making a difference through their leadership. Annual Meeting of the American Educational Research Association 1-3. San Diego.

Tokuhama-Espinosa, T. (2003): The Multilingual Mind: Issues Discussed by, for and about People Living with Many Languages. Praeger Publishers, CT.

Trethewey, A. (1993): "On Visiting School Systems Overseas." Journal of Educational Administration 10(1): 88-94.

Vanderplank, R. (1988): "The value of teletext sub-titling in language learning." ELT Journal 42: $272-281$

Weighting, J.M, D.L. Nisbet and E.R. Tindall (2005): "Exploring a Summer English Language Camp Experience in China: A Descriptive Case Study." Asian EFL Journal 7(4): 85-108. 